\title{
UM OLHAR SOBRE OS DOCENTES DOS CURSOS TÉCNICOS EM RADIOLOGIA
}

\author{
R. O. SANTOS E S. R. OLIVEIRA \\ Escola Politécnica de Saúde Joaquim Venâncio (EPSJV/Fiocruz) \\ rosantos.radiologia@gmail.com*
}

Artigo submetido em outubro/2014 e aceito em dezembro/2014

DOI: 10.15628/rbept.2014.3564

\section{RESUMO}

O objetivo deste artigo é apresentar o desenvolvimento preliminar das reflexões sobre o perfil dos docentes e de suas práticas pedagógicas nos cursos técnicos em radiologia. Do surgimento dos cursos para habilitação do operador de raios X, em 1957, à regulamentação profissional, em 1985, os cursos técnicos expandiram-se sobremaneira. A procura por docentes aumentou, e os programas de licenciatura não foram capazes de suprir a demanda. Diante disso, a experiência em serviço tornou- se o único requisito à prática docente. É nesse contexto que se insere o trabalho docente nos cursos técnicos em radiologia. Quais os atributos relevantes para uma educação que valorize a formação integral do trabalhador? Como conceber uma prática pedagógica consciente dos aspectos sócio-históricos do trabalho que tenha o aporte teórico-metodológico necessário à uma prática mais crítica na educação profissional?

PALAVRAS-CHAVE: cursos técnicos, radiologia, práticas pedagógicas, perfil docente.

\section{A LOOK ON THE TEACHERS OF TECHNICAL COURSES IN RADIOLOGY}

\begin{abstract}
The purpose of this paper is to introduce the preliminary development of reflections on the teachers' profile and their teaching practices in technical courses in radiology. From the arising of courses for qualification of the x-ray operator in 1957 to the professional regulation in 1985, the technical courses have expanded greatly. The demand for teachers increased and degree programs were not unable to compensate her. Therefore, the experience at work has become the only requirement for
\end{abstract}

teaching practice. It is in this context that the teaching in technical courses in radiology is placed. Which attributes are important for an education that values the integral formation of the workman? How to design a pedagogical conscious practice of socio-historical aspects of the work that also provides the theoretical and methodological support necessary for a more critical practice in professional education?

KEYWORDS: technical courses, radiology, teaching practices, teacher profile 


\section{INTRODUÇÃO}

Dos primeiros estudos com raios catódicos à descoberta dos raios $X$ - realizada pelo físico alemão Wilhelm Conrad Roentgen, em 1895 -, muitos estudos foram desenvolvidos para fins de adequação dessa nova radiação ao diagnóstico médico. Após a disseminação das práticas médicas com raios $\mathrm{X}$, foi necessário organizar os primeiros processos formativos para sistematizar a qualificação dos trabalhadores.

Inicialmente, cursos de radiologia eram ministrados por médicos e "ofertados de forma pontual, predominando a formação em serviço" (OLIVEIRA et al., 2013, p.210), que não caracterizava um processo educativo formal. O "avanço das técnicas em radiologia médica diagnóstica e terapêutica, e a crescente expansão de médicos especializados ocasionaram aumento na demanda por auxiliares" (ibid, p.211), tornando o treinamento de recursos humanos para operar com raios $X$ cada vez mais necessário. Nesse sentido, foi concebida as ocupações de auxiliar de raios $X$ e de práticos em saúde, em que trabalhadores assistiam os médicos durante os procedimentos diagnósticos. No entanto, segundo Ferreira Filho, a "formação dos realizadores de tal tarefa (realizar radiografias) tinha como suporte o aprender fazendo por meio do método mestre-aprendiz" (2010, p.31), ou seja, o mestre de ofícios era quem possibilitava ao trabalhador o desenvolvimento e o domínio do ofício, ainda caracterizando capacitação em serviço.

Após a sanção da primeira lei que tratava sobre os trabalhadores dos raios X, em 1950, foi determinado o cargo de operador de raios X para os auxiliares médicos. Em 1957, o Serviço Nacional de Fiscalização da Medicina e Farmácia (SNFMF) foi criado, por meio do decreto $\mathrm{n}$. 41.904/57, em que tinha por competência fiscalizar o trabalho em saúde e certificar os trabalhadores. Assim, o exercício do ofício de operador de raios $\mathrm{X}$ passa a ser condicionado à uma habilitação obrigatória, por meio de uma avaliação certificativa, em que eram realizadas provas orais, práticas e escritas com os trabalhadores para fins de habilitação e registro profissional (BRASIL, 1957). A partir desse momento, observa-se a necessidade de uma estrutura educacional mínima, para controle da aprovação nessas avaliações.

Paralelamente, surgem os primeiros cursos de iniciativa privada, como meio preparatório para a esse exame, que era pré-requisito à obtenção do registro profissional. Esse tipo de procedimento ainda não caracterizava capacitação formal, visando mais à fiscalização do exercício profissional do que, de fato, à formação (FERREIRA FILHO, 2010). As primeiras escolas voltadas para formação do operador de raios X surgem entre 1950 e 1960, em quantidades reduzidas e exigiam um nível de escolaridade muito baixo, o que desfavorecia o ensino de conceitos mais complexos, priorizando os treinamentos em serviço (ibid). Esse processo de capacitação e regulamentação da profissão do técnico em radiologia passa a ser oficial a partir da sanção da lei n. 7.394, em 1985 (BRASIL, 1985).

Com a regulamentação da lei n. 9.394/96 (LDB) e do decreto n. 2.208/97, os cursos técnicos expandiram-se sobremaneira. Esses documentos autorizam os cursos técnicos subsequentes ao ensino médio, regulamentando a Educação Profissional Técnica e Nível Médio (EPTMN) e permitindo a expansão das escolas-curso para formação técnica isolada, que passa a alcançar não somente os egressos do ensino médio, mas também todos os trabalhadores que necessitavam de requalificação para se adequarem ao mercado, cada vez mais flexível e instável. Desde então é que a procura por docentes aumentou, fazendo com que os programas de licenciatura não 
suprissem a demanda. A experiência em serviço, portanto, passa a ser o único requisito à prática docente no âmbito da educação profissional.

Como consequência dessa falta de critérios para a admissão, os professores que se inseriam nos cursos não eram - e ainda não são - devidamente qualificados para exercer a atividade pedagógica. De uma maneira geral, na formação técnica dos professores da educação profissional, identifica-se, entre outros problemas, a dificuldade de se atualizarem em suas áreas profissionais, o que aponta para a necessidade de uma formação não só inicial - e pedagógica -, mas contínua, em serviço (PETEROSSI, 1994). Isso também ocorre no campo da radiologia.

Considerando os aspectos até aqui mencionados, levanto as seguintes questões: quais os atributos relevantes para uma educação que valorize a formação integral do trabalhador? Como conceber uma prática pedagógica consciente dos aspectos sócio-históricos do trabalho que tenha o aporte teórico-metodológico necessário a uma prática mais crítica no ensino técnico? Essas indagações nortearão a nossa busca por compreender quem é esse professor e de que forma sua prática docente se construiu nesse percurso histórico. Apesar das duras condições de trabalho impostas pelo contexto político e pelo modo de produção capitalista, a hipótese é de que o professor desempenha um papel estratégico na formação desses trabalhadores e, por meio da recontextualização de seu discurso pedagógico (BERNSTEIN, 2003) e de uma formação pedagógica para a docência, pode contribuir no projeto emancipatório de educação.

O objetivo do presente artigo é apresentar as reflexões preliminares sobre a pesquisa que tenho desenvolvido como mestrando, sobre o perfil dos docentes dos cursos técnicos de radiologia e de suas práticas pedagógicas. Nesta, visamos a traçar o perfil dos docentes dos cursos técnicos de nível médio em radiologia, descrever as práticas pedagógicas mais recorrentes e discutir o processo de qualificação docente na área, de modo que se produzam críticas ao modelo vigente e novas propostas de formação para esses professores.

A presente pesquisa torna-se relevante por pretender revelar as características do trabalho desses profissionais e a forma como influenciam na formação dos técnicos. Além disso, uma formação social e política possibilitaria um ensino para além do treinamento de rotinas e protocolos, promovendo uma profunda transformação na consciência dos que se candidatam à posição de professores. Inicialmente, a partir de uma análise da prática dos professores dentro de escolas em que trabalho foi possível perceber algumas relações com os problemas encontrados na formação do técnico em radiologia. Em seguida, consultas a diversas bases de dados não revelaram pesquisas específicas acerca da prática docente nos cursos de radiologia, mas acerca de trabalhos de caráter técnico.

Em pesquisas anteriores, Ferreira Filho (2010) e Lopes (2013) sinalizaram problemas no processo formativo e na percepção do trabalhador técnico do campo da Radiologia. Sabendo que o professor está situado no cerne do processo formativo, uma análise detalhada do seu perfil e das práticas pedagógicas desenvolvidas em sala de aula torna-se fundamental.

Em oposição ao modelo educacional existente, Ferreti (2009) apresenta uma proposta ${ }^{1}$ baseada nos manuscritos do pensador Karl Marx e na concepção de politecnia, cuja ideia é se

\footnotetext{
${ }^{1}$ Vale ressaltar que a concepção marxiana de educação não foi concebida em seu sentido didático-pedagógico, mas sim, segundo Ferreti (2009), sob uma perspectiva histórica e sociopolítica. Apesar disso, considero importante proposta para a formação de um legítimo profissional, que compreenda e domine o processo produtivo com
} 
desenvolver uma formação integral, visando o domínio das ciências para além do manejo da maquinaria, proporcionando também condições para a organização e controle do processo produtivo e a expressão da criatividade e subjetividade humana na resolução dos problemas cotidianos. Nessa lógica de educação, integral e com uma perspectiva sócio-histórica do trabalho, caberia ao professor não somente o papel de participar do desenvolvimento científico das habilidades profissionais, mas também de atuar politicamente por meio de práticas docentes que reconheçam a diversidade social entre os alunos, valorizando as particularidades de cada grupo. Para que isso seja possível, é importante repensar a trajetória de formação desse professor.

Por acharmos importante que essa formação integral comece pelos docentes, alertamos para a necessidade do estabelecimento de diretrizes que garantam uma formação docente na educação profissional (PACHECO, 2012), no formato de licenciatura, que permita a construção de identidade própria a esses professores, com conhecimentos aprofundados sobre trabalho, ciência, tecnologia, cultura e desigualdades sociais do mundo moderno. Além disso, seria possível que a formação integral se estendesse também aos alunos, por meio de uma prática pedagógica mais crítica e que reflita também os conflitos sociais em que se engendram, e não somente reflexiva quanto à sua capacidade produtiva (RAMOS, 2009).

\section{REVISÃO BIBLIOGRÁFICA}

Na perspectiva do trabalho docente e das práticas pedagógicas, o saber e a prática docente são compostos por vários níveis de complexidade, pois estão envoltos em valores e aspectos distintos. O trabalho do professor em sala de aula abrange aspectos culturais, sociais e históricos, caracterizando-se como um ato essencialmente político (FREIRE, 1989). A ação educativa pode ser sistematizada em razão da interação desses fatores, de modo que ocorra tanto em espaços formais quanto informais, portanto reconheço que não somente a escola seja o espaço adequado para desenvolver o ato educativo, mas também o ambiente de trabalho, embora sem a devida sistematização.

A grande questão, portanto, é entender se existe especificidade na formação dos professores para a educação profissional. É importante, antes de tudo, admitir que esse profissional também é professor e, como tal, precisa de uma formação avançada e não somente uma perspectiva especializada (SANTOS \& FURTADO, 2011), que alude às questões de fragmentação/complementação do conhecimento. De acordo com Schön (2000), a formação do professor para a educação profissional, assim como para toda formação docente, deve priorizar o domínio do trabalho e desenvolvimento intelectuais de modo a favorecer a capacidade de criação de novos conhecimentos e conceitos relacionados a uma determinada prática.

No contexto das Escolas de Aprendizes e Artífices - ainda na década de 1940 - identificase, conforme Peterossi (1994), os professores normalistas e os profissionais recrutados das oficinas e fábricas para lecionar, para ensinar o "aprender trabalhar". É possível associar os normalistas aos professores da formação geral e os profissionais recrutados do mercado aos nossos atuais "profissionais-professores". Com relação aos últimos, é evidente a falta de uma base teórica, de

autonomia, consciente de sua posição social, política e cultural na sociedade e de sua capacidade de transformação da mesma. 
conhecimentos técnicos e pedagógicos, que se tornam empecilhos para uma prática docente mais sólida, predominando a reprodução das práticas laborais nas salas de aula ou em oficinas-modelo, implantadas nas próprias escolas.

Os professores 'não normalistas' traziam como diferencial de sua formação a bagagem de experiência profissional, vivenciada na prática ou as experiências obtidas em seu curso inicial de formação para o trabalho, o que transformava as instituições de ensino formal nas primeiras oficinas-escolas (SANTOS \& FURTADO, 2011), aproximando-se muito do modelo vigente de escolas-curso, evidentes após a LDB n. 9.394/96 e ao decreto n. 2.208/97, com a possibilidade legal da oferta dos cursos técnicos subsequentes ao Ensino Médio. No entanto, não havia uma sistematização nesse tipo de prática. Assim, a ausência do caráter pedagógico e científico inviabilizava a construção de novos conhecimentos e sua problematização com as situações reais de trabalho.

No período de 1942 - com a Lei Orgânica do Ensino Industrial - até 1961, antes da LDB n. 4.024/61, não havia uma sistematização acerca da formação docente, por mais que as diretrizes dessa lei mostrassem a importância da elevação do nível de conhecimento dos professores e de sua competência pedagógica. A partir da LDB, a formação docente para o ensino técnico recebe as primeiras diretrizes que, no entanto, não se davam da mesma forma que a relacionada aos professores do ensino médio, mas estava ligada a cursos especiais em caráter emergencial por causa da falta de recursos humanos para a demanda técnica. Segundo Peterossi (1994), acentuase a dualidade educacional também na formação docente, uma vez que passa a existir uma dicotomia ensino técnico e ensino médio e formações distintas para cada perfil de professor. Em 1968, com a lei n. 5.540, se estabelece a formação para o magistério em nível superior como padrão para ambos, ainda que as universidades estivessem despreparadas para isso.

Entre propostas de cursos de curta duração para a capacitação pedagógica e disputas de projetos legais para a consolidação da formação docente - em nível geral e técnico - se delineiam as primeiras diretrizes legais para a formação do magistério, unificada também ao nível técnico. Assim, por meio da portaria n. 432/71, são criados os Cursos de Esquema I e II, justificados pela compulsoriedade da profissionalização conferida ao 2o grau, na lei n. 5.692/71. Em razão da necessidade da formação docente em nível superior, imposta por essa lei, os Cursos de Esquema sofrem modificações e, com a Resolução CFE n. 3/77, passaram a se configurar em cursos de licenciatura plena.

Diante dos avanços e retrocessos no período pré-redemocratização, os traços de continuidade permaneceram. O decreto n. 2.208/97 determinava, em seu artigo 9o, que as disciplinas técnicas poderiam ser ministradas por instrutores e monitores, trazendo à tona o aspecto pontual do preparo desses professores. Além disso, Santos e Furtado (2011) entendem que os professores, nesse contexto,

deveriam ser selecionados principalmente pela experiência profissional, que a preparação para o magistério não precisaria ser prévia, pois poderia dar-se em serviço, e manteve a admissão de programas especiais de formação pedagógica (p. 66).

Saliento, à luz do decreto n. 5.154/04, a necessidade em rever a formação de professores de forma a articular-se com os campos de conhecimento da educação profissional. Além disso, 
uma licenciatura como formação docente para a educação profissional faz-se importante, uma vez que a formação de trabalhadores se dá em caráter inicial e continuado, ocorrendo também em programas de pós-graduação (SANTOS \& FURTADO, 2011).

Nessa perspectiva, seria importante um aprofundamento teórico, metodológico e técnico da formação inicial, além de uma formação humana e social acerca do processo ensinoaprendizagem e uma elevação da capacidade intelectual, científica e investigativa do docente, por meio de uma formação "capaz de integrar trabalho, ciência, técnica e tecnologia, humanismo e cultura geral, buscando o enriquecimento científico, cultural, político e profissional das pessoas que atuam nessa esfera educativa" (SANTOS \& FURTADO, 2011, p.68), resultando na preparação de sujeitos providos de autonomia intelectual, ética e política, preparados para atuarem no contexto de disputas que envolvem a formação de trabalhadores.

Sobre o processo formativo no campo da radiologia, Ferreira Filho (2010) aponta que a educação profissional na área deve ter "o entendimento da educação enquanto prática social que incluem dimensões políticas e éticas na busca da formação de um ser humano integral" (ibid, p.87). Isto é, o técnico no seu campo de trabalho não pode representar "apenas uma subordinação ao avanço tecnológico" (ibid, p.83), mas deve ir além do manuseio de equipamentos para que haja uma posição crítica diante da realidade. $O$ atual processo de formação, portanto, não atende às reais necessidades da prática profissional em radiologia.

De forma preliminar e muito incipiente, sobre os docentes dos cursos de radiologia, Ferreira Filho (2010) aponta, entre outras práticas, o ensino de múltiplas disciplinas pelo mesmo professor, muitas vezes sem bagagem teórica suficiente para isso. Observou-se ainda "uma inexistência de critérios para o exercício docente nas instituições, o que deprecia especificidades no aporte do conhecimento direcionado aos alunos" (ibid, p.70). Em razão dessa "multiplicidade de disciplinas" ministradas pelo mesmo professor, as ferramentas pedagógicas e a abordagem teórico-prática insuficiente "podem ser impróprios, inadequados, inespecíficos [...] e, isso incide de modo direto ou indireto" sobre a formação do aluno (ibidem). Por fim, o autor ressalta que "existe uma carência nesse profissional técnico de ter conhecimento e domínio do componente pedagógico, para assim melhor conduzir o processo ensino/aprendizagem" (ibid, p.84). Esses aspectos reforçam a necessidade de uma análise mais aprofundada do assunto, corroborando minha tese de que os docentes precisam ser inseridos em uma nova lógica pedagógica.

\section{METOdOLOGIA}

Trata-se de uma pesquisa de campo, qualiquantitativa, estruturada no formato de estudo de caso. $\mathrm{O}$ uso de revisões bibliográficas e análise documental tornam-se necessários para delimitar o recorte histórico do trabalho docente no campo da saúde. Com relação ao trabalho de campo, foram elaborados questionários de roteiro semiestruturado. A abordagem dos participantes está sendo será mediada por um Termo de Consentimento Livre e Esclarecido (TCLE) e a aplicação dos questionários se dará de duas formas: presencialmente, por meio de questionários impressos; ou à distância, por meio de questionários digitais.

No que se refere aos questionários impressos, foi realizado o mapeamento dos cursos em que os professores atuam e realizados os primeiros contatos para agendar a data da abordagem. No encontro presencial, o questionário é entregue, a ser preenchido de forma manuscrita e é 
estipulado um prazo para a devolução. Com relação à abordagem à distância, os questionários seriam disponibilizados com data predefinida para entrega e coletados por meio de correio eletrônico - e-mail - ou por meio do contato pelas redes sociais. Primeiramente, foi realizado um levantamento de endereços de e-mail e perfis de rede social desses docentes - foi utilizado o Facebook $^{\circledR}$-, para os quais os arquivos seriam enviados. Para construção e gerenciamento dos questionários, foi utilizada a ferramenta Google Forms ${ }^{\circledR}$.

A aplicação desse questionário permitirá, inicialmente, a obtenção de dados socioeconômicos e culturais dos participantes, que possibilitarão organizar o perfil docente sob vários aspectos, tais como: gênero, localidade, faixa etária, dentre outros. O questionário consistirá em perguntas fechadas e abertas. Questões fechadas, por um lado, resultam em respostas limitadas a opções específicas e previamente definidas, o que facilitará análises estatísticas e a categorização dos dados. Por outro lado, as questões abertas proporcionam respostas que representam a expressão da opinião do sujeito em seus detalhes, o que irá permitir e facilitar análises qualitativas. Para assegurar a compreensão e interpretação das questões, os objetivos da pesquisa serão explicados previamente ao participante e as questões serão claras, objetivas e com uma construção textual simples.

\section{RESULTADOS E DISCUSSÕES}

No caso da radiologia, observa-se que existem, em tese, três perfis de professores nos cursos técnicos, a saber: o recém-formado dos cursos técnicos ou superiores de tecnologia (CST); o profissional proveniente dos postos de ocupação e o profissional graduado em outras áreas da saúde, que também atua nos cursos técnicos de radiologia.

Com relação aos professores recém-formados, sua prática tende a se pautar na transmissão de seus conhecimentos teóricos, visando a articular o conteúdo apreendido em sua formação com o material técnico (livros e outras ferramentas) selecionado para a ministração das aulas. Esta forma de atuação não atende, efetivamente, às necessidades dos alunos por dois motivos específicos. O primeiro aponta à ausência de fundamentos pedagógicos na formação desse professor. Nesse caso, a falta de uma formação docente não permite uma prática didáticopedagógica mais ampla, o que contribuiria para o aprendizado dos alunos. $O$ segundo se refere à falta de experiência do professor com a prática em serviço, prejudicando a associação da teoria ensinada com a prática efetiva no campo profissional. Consequentemente, os alunos tendem a aprender a trabalhar em serviço, com treinamentos e o acompanhamento dos profissionais mais experientes (LOPES, 2013).

Por sua vez, analisando os professores provenientes dos postos de trabalho, é possível observar que, em suas aulas, voltam-se a reproduzir técnicas de serviço desenvolvidas nos postos de ocupação. Isso se dá, muitas vezes, porque esse técnico dispõe apenas de sua experiência acumulada ao longo dos anos ou dos diversos contextos de trabalho vivenciados, embora sua prática profissional devesse ser uma ação humana, de caráter laboral, embasada e sistematizada por princípios e fundamentações teóricas mais amplas. Essa lógica desencadeia em sala uma proposta pedagógica que pretende apenas "ensinar a trabalhar", reduzindo o conhecimento técnico-científico às necessidades do posto de trabalho e conformando o ensino ao processo produtivo. Assim, ao que tudo indica, a próxima geração de técnicos em radiologia, oriunda desse sistema de formação aligeirada, tenderá ainda mais a reduzir o que se aprendeu para se adequar 
às condições de trabalho, e assim sucessivamente. Em suma, esse tipo de prática docente, evidentemente, pode desqualificar tanto o processo de formação quanto, consequentemente, o próprio trabalhador.

Já profissional graduado com licenciatura em áreas correlatas parece desenvolver uma prática docente módica, pela falta de conhecimentos específicos da área. É comum encontrarmos, por exemplo, professores com formação acadêmica em Física ou Biologia com dificuldades em conduzir suas aulas por falta de conhecimentos de ordem teórica e prática do trabalho com técnicas radiológicas, mesmo com todo o aporte de sua formação acadêmica. Portanto, a falta de uma formação básica em radiologia - seja em nível técnico ou superior -, dificulta sua habilitação para lecionar nos cursos da área, tanto em disciplinas gerais como em disciplinas específicas.

É importante, assim, traçar o perfil dos professores para discutir o processo de qualificação docente na área, propondo críticas ao modelo vigente e novas discussões sobre a formação docente para esses cursos. Para que isso seja possível, novas pesquisas devem se debruçar sobre a EPTMN, estabelecendo não apenas relações entre sua trajetória histórico-política no Brasil e o processo de capacitação dos docentes, para o campo da saúde e da radiologia especificamente, mas também envolvendo outros tipos de problema como, por exemplo, por que cursos como esses são oferecidos em sua maioria por escolas da rede privada etc.

Embora as questões políticas, socioeconômicas e culturais interfiram direta e indiretamente no trabalho do professor, é preciso analisar qual dos projetos de formação profissional em disputa tem-se privilegiado com as atuais políticas de qualificação docente: a qualificação para o mercado ou para a integralidade humana.

Com a pesquisa em andamento, ainda não podemos responder, de forma categórica, o problema da pesquisa. No entanto, acreditamos, com o pouco que alcançamos, que se deve dar uma maior atenção à formação desses professores que atuam na educação profissional.

\section{CONCLUSÃO}

No que se refere aos perfis inicialmente identificados, observa-se a diversidade pedagógica em razão da falta de uma legislação específica para a formação docente na educação profissional. Essa questão, por sua vez, corrobora uma formação de trabalhadores sujeita a uma lógica de mercado que reproduz desigualdades em razão das demandas produtivas, cada vez mais flexíveis.

Entendo, nesse sentido, que não bastaria uma capacitação pedagógica, que apenas se comprometesse em complementar a formação do profissional das técnicas radiológicas e habilitálo ao ensino. Considero necessária uma nova concepção de formação docente, cujos princípios fossem a recontextualização de sua formação inicial e o aprofundamento teórico-metodológico dos conhecimentos em sua formação profissional para além da aquisição de conhecimentos pedagógicos, abrangendo dimensões sociais e culturais.

Muito ainda tenho a investigar, todavia, não tenho pretensão - nem aqui nem em minha pesquisa de mestrado - de esgotar a complexidade da questão. Entretanto, visamos a mudança de um grupo de trabalhadores que está à margem, sem esperança e a tomar posse de um posto de trabalho considerado não qualificante. Mesmo assim, entendo que é possível, por meio da recontextualização, transformar a realidade mediante a luta e a resistência da classe trabalhadora. 


\section{REFERÊNCIAS}

1. BERNSTEIN, B. A pedagogização do conhecimento: estudos sobre recontextualização. Cad.Pesq. v.120, 2003, p.75-110.

2. BRASIL. Lei 1.234 de 14 de novembro de 1950. Confere direitos e vantagens a servidores que operam com Raios X e substâncias radioativas. Disponível em: https://www.planalto. gov.br/ccivil_03/leis/1950-1969/I1234.htm. Acesso em: 17 de out.2014.

3. __ Lei $n^{\circ} 4.024$, de 20 de dezembro de 1961. Estabelece as diretrizes e bases da educação nacional. Disponível em: www.planalto.gov.br/ccivil_03/leis/19394.htm. Acesso em: 15, jan. 2015.

4. L Lei no 5.540, de 28 de novembro de 1968. Fixa normas de organização e funcionamento de ensino superior e sua articulação com a escola media, e dá outras providências. Disponível em: <http://www6.senado.gov.br/sicon/\#>. Acesso em: 10, abr., 2010.

5. L_ Lei no 7.394 de 29 de outubro de 1985. Regula o Exercício da Profissão de Técnico em Radiologia. Disponível em: http://www.planalto.gov.br/ccivil_03/leis/ 17394.htm. Acesso em: 17 de out.2014.

6. _. Lei $n^{\circ} 9.394$, de 20 de dezembro de 1996. Estabelece as diretrizes e bases da educação nacional. Disponível em: www.planalto.gov.br/ccivil_03/leis/19394.htm. Acesso em: 15, jan. 2015.

7.

. Decreto no 41.904, de 29 de julho de 1957. Aprova o Regimento de Serviço Nacional de Fiscalização da Medicina e Farmácia, do Ministério da Saúde. Disponível em: http://www2.camara.leg.br/legin/fed/decret/1950-1959/decreto-41904-29-julho-1957380811-norma-pe.html. Acesso em: 31, mai. 2015.

8.

Decreto no 2.208 de 17 de abril de 1997. Regulamenta o §2 do art. 36 e os arts. 39 a 42 da Lei $n$ o 9.394, de 20 de dezembro de 1996, que estabelece as diretrizes e bases da educação nacional. Disponível em: http://www.planalto.gov.br/ccivil_03/decreto/D2208.htm. Acesso em: 15, jan. 2015.

9. Decreto № 5.154 de 23 de julho de 2004. Regulamenta o §20 do art. 36 e os arts. 39 a 41 da Lei no 9.394, de 20 de dezembro de 1996, que estabelece as diretrizes e bases da educação nacional e dá outras providências. Disponível em: http://www.planalto.gov.br/ ccivil_03/_ato2004-2006/2004/decreto/d5154.htm. Acesso em: 15, jan. 2015.

10.

Portaria Ministerial no 432, de 19 de junho de 1971. Fixa normas para cursos superiores de formação de professores de disciplinas especializadas do ensino médio. Documenta, Rio de Janeiro, n.128, p. 193-197, jul. 1971.

11. _. Resolução CFE no 3, de 25 de fevereiro de 1977. Dispõe que a graduação de professores para a parte de formação especial do currículo do ensino de 20 grau far-se-á em curso de licenciatura plena ministrado por estabelecimentos de ensino superior. Disponível em: http://www.prolei.inep.gov.br/anexo.do?URI=http\%3A\%2F\%2Fwww.ufsm.br\%2Fcpd\%2 Finep\%2Fprolei\%2FAnexo\%2F-2748184364143993471. Acesso em: 11, abr., 2010.

12. Resolução CNE/CEB no 2/97, de 7 de julho de 1997. Dispõe sobre os programas especiais de formação pedagógica de professores para as disciplinas do currículo do ensino fundamental, do ensino médio e da educação profissional em nível médio. Disponível em: 
http://portal.mec.gov.br/setec/arquivos/pdf_legislacao/tecnico/legisla_tecnico_resol02_26j unho_1997.pdf. Acesso em: 31, jan. 2015

13. FERREIRA FILHO, J.L. Formação do profissional de radiologia em nível técnico na região metropolitana do Rio de Janeiro: Um estudo exploratório. 2010, 100f. Dissertação (Mestrado Profissional em Educação Profissional em Saúde) - Escola Politécnica de Saúde Joaquim Venâncio, Fundação Oswaldo Cruz, Rio de Janeiro, 2010.

14. FERRETI, C.J. O pensamento educacional em Marx e Gramsci e a concepção de politecnia. Trabalho, Educação e Saúde, Rio de Janeiro, v. 7, supl.1, p. 105-128, 2009.

15. FREIRE, P. A importância do ato de ler: em três artigos que se completam. 23.ed. São Paulo: Autores Associados/Cortez, 1989.

16. LOPES, S.O.F. Formação e trabalho em saúde: uma análise a partir da percepção de Técnicos em Radiologia. 2014, 80f. Dissertação (Mestrado Profissional em Educação Profissional em Saúde) - Escola Politécnica de Saúde Joaquim Venâncio, Fundação Oswaldo Cruz, Rio de Janeiro, 2013.

17. OLIVEIRA, S.R. et al.. Qualificação dos Técnicos em Radiologia: história e questões atuais. In: MOROSINI, M.V.G.C.et al. (Orgs.). Trabalhadores Técnicos da Saúde: aspectos da qualificação profissional no SUS. Rio de Janeiro: EPSJV, 2013.

18. PACHECO, E (Org.). Perspectivas da Educação Profissional Técnica de Nível Médio: proposta de Diretrizes Curriculares Nacionais. São Paulo: Moderna, 2012.

19. PETEROSSI, H.G. Formação do professor para o ensino técnico. São Paulo: Loyola, 1994.

20. RAMOS, M.N. Concepções e práticas pedagógicas nas escolas técnicas do Sistema Único de Saúde: fundamentos e contradições. Trabalho Educação e Saúde, v. 7, n. 1, 2009, p.153-73.

21. SANTOS, S.F.R; FURTADO, E.D.P. O professor da educação profissional: desafios nas práticas pedagógicas. B.Téc.Senac: Rev. Educ. Prof., Rio de Janeiro, v. 37, no 1, 2011, p.61-71.

22. SCHÖN, D.A. Educando o profissional reflexivo: um novo design para o ensino e a aprendizagem. Porto Alegre: Artmed, 2000. 